\author{
Carla Peñaloza Palma \\ Universidad de Chile, Chile
}

\title{
Duelo callejero: mujeres, política y derechos humanos bajo la dictadura chilena (1973-1989)
}

\begin{abstract}
Resumen: Las mujeres familiares de las víctimas de la dictadura chilena se organizaron muy tempranamente para buscar a sus seres queridos y exigir verdad y justicia. Sin embargo, los estudios feministas las han relegado al rol de mujeres-madres que salen por primera vez de sus casas para cumplir un rol tradicional, como es el de cuidar a sus familiares, sin otorgarles un carácter político a sus movilizaciones. En este trabajo, planteamos poner en discusión este análisis, proponiendo que jugaron un rol muy importante en la defensa de los derechos humanos, así como también en la rearticulación del tejido social destruido tras el golpe de Estado. Ellas se convirtieron en actores políticos de primera línea en el espacio público para exigir la verdad sobre el paradero de sus seres queridos, interpelando al régimen y su legitimidad, defendiendo, de esa forma, los derechos humanos confiscados a todos los chilenos. Palabras Claves: Mujeres; dictadura; derechos humanos; feminismo.
\end{abstract}

Esta obra tem licença Creative Commons.

\section{Introducción}

El 11 de septiembre de 1973 el golpe de Estado encabezado por el General Pinochet puso fin al proyecto de la 'vía chilena al socialismo', al derrocar al presidente constitucional Salvador Allende, líder de la Unidad Popular, coalición que reunía a comunistas, socialistas, Movimiento de Acción Popular Unitaria, Izquierda Cristiana, entre otros partidos y movimientos de izquierda, que habían emprendido un programa de importantes y profundas transformaciones sociales y políticas que favorecía a los más pobres del país.

Los golpistas constituyeron un nuevo Poder Ejecutivo, encabezado por la Junta de Gobierno, compuesta por el general Augusto Pinochet Ugarte, Comandante en Jefe del Ejército; el almirante José Toribio Merino, quien se autoproclamó Comandante en Jefe de la Armada; Gustavo Leigh Guzmán, de la Fuerza Aérea y César Mendoza, autoproclamado Director General de Carabineros. Se disolvió el Congreso - pasando a ejercer las labores legislativas la propia Junta 
Militar -, se proscribieron los partidos que conformaban la Unidad Popular, y se declaró en receso al resto de los partidos políticos, se incineraron los registros electorales, se decretó la cesación de alcaldes y regidores, se exoneraron funcionarios públicos, se controlaron los sindicatos y se intervinieron las universidades. Junto con esto, el Poder Legislativo perdió en los hechos su independencia, actuando desde ese momento bajo la tutela de la Junta Militar.

Por otra parte, los medios de comunicación cercanos al gobierno de la Unidad Popular fueron clausurados y el resto fue sometido a la censura, o eran adictos al régimen, por lo que se pusieron a su servicio. La Junta declaró el "Estado de Sitio en tiempos de Guerra", amparada en la Constitución de 1925 que "proporcionaba amplios poderes a la Junta de Gobierno y subordinaba el Poder Judicial a las decisiones del poder político".' Esa misma constitución fue derogada por la vía de los hechos.

Estas medidas instauraron una dictadura que actuó con absoluta impunidad para cometer graves violaciones a los derechos humanos que creó una sensación de indefensión y temor dentro de la sociedad chilena. Junto con el asesinato a opositores políticos se instauró una de las formas más crueles de represión. La detención forzada de personas.

La oposición a la dictadura y las acciones de protesta no se hicieron esperar. Lo primero fue la sobrevivencia y la defensa de los derechos humanos. La primera organización fue la Agrupación de Familiares de Detenidos Desaparecidos (AFDD), formada fundamentalmente por las mujeres vinculadas a las víctimas. Desde entonces y hasta hoy, han luchado incansablemente por localizar el paradero de sus seres queridos, buscar la verdad y exigir el pronunciamiento de la justicia. Lo que comenzó como una acción de denuncia se transformó con el tiempo en la batalla más decisiva contra el olvido.

No fue fácil salir a las calles a luchar contra la dictadura, sobre todo en los primeros años, pero lo hicieron, y poco a poco se fueron sumando otros actores. En los años ochenta del siglo XX las mujeres chilenas, al igual que muchos otros sectores de la sociedad, salieron a las calles para manifestarse contra la dictadura de Pinochet, que llevaba para entonces una década en el poder. La dictadura no daba signos de debilidad, por el contrario, a través de un plebiscito sin garantías legales, había hecho aprobar en 1980 una constitución antidemocrática en su esencia, y que contenía en sus mismas reglas enormes dificultades para ser modificada en el futuro. La carta constitucional trazaba un camino de institucionalización del régimen que culminaría en 1988 con un plebiscito donde los ciudadanos se manifestarían a favor o en contra del general Pinochet. Si 
${ }^{2}$ HUNNEUS, 2000, p. 511. ganaba, renovaba su mandato por ocho años más. Estas medidas iban acompañadas de las refor-mas económicas más radicales realizadas en Chile hasta entonces, inspiradas en el modelo neoliberal de los Chicago boys, que supuestamente ofrecerían mayor bienestar material a la población, lo que aseguraría la continuidad del régimen. Los primeros años de la dictadura habían estado caracterizados por una represión hasta entonces desconocida en Chile. Más de cuatro mil personas fueron ejecutadas o hechas desaparecer, la mayoría de ellas en los primeros meses tras el golpe militar. Para la década de los años ochenta, el terrorismo de Estado había logrado unos de sus principales objetivos, la desarticulación del tejido político-social que había llegado a su máxima expresión en términos de organización y conquistas populares en el gobierno del presidente Salvador Allende. Fue desterrada cualquier señal de lo que había sido el estado de bienestar, construido desde los años 30 del siglo XX. Fue privatizada la salud, la educación, las pensiones de vejez y jubilación, entre otras, y fueron reducidos a un mínimo histórico los derechos de los trabajadores y de la población en general.

Las reformas económicas, unidas a la recesión mundial del año 1982, no dieron los frutos esperados por la dictadura. Por el contrario, la reducción del Estado a su mínima expresión agudizó sus efectos. Para 1982 las cifras oficiales de desempleo alcanzaron un $19,6 \%$, pero en la práctica alcanzaba el $26,4 \%$, y para 1983 había llegado al 31,3\%. ${ }^{2}$ El aumento del desempleo, la falta de democracia y el atropello persistente a las libertades públicas y los derechos humanos se conjuraron para dar fuerza al descontento contra el régimen, que en estos años se manifestó de manera más masiva y más visible en el espacio público. Trabajadores, estudiantes, pobladores, mujeres, entre otros sectores de la sociedad, salieron a las calles en el contexto de las convocatorias a las jornadas de protesta nacional, que se sucedieron casi mensualmente entre 1983 y 1986, para luchar por sus demandas particulares y poner fin a la dictadura.

El movimiento de mujeres jugó un rol muy importante en este proceso, vinculando sus demandas con el movimiento de defensa de los derechos humanos, y la unidad de la oposición, como fue el movimiento "mujeres por la vida", que agrupaba a mujeres de diferentes partidos políticos desde el centro a la izquierda e independientes. También el movimiento feminista chileno tuvo una presencia importante en este proceso, instalando, además, un discurso y demandas propias del feminismo en un país donde hablar de derechos estaba prohibido. La consigna "democracia en el país y en la casa" fue instalada con fuerza, develando un problema que no empezaba ni acababa con la dictadura, sino que se 
${ }^{3}$ Olga POBLETE, 1993, p.144.

vinculaba con las profundas desigualdades de género, transversales a toda la sociedad, y era necesario discutirlo en esa perspectiva. Lo personal es político, señalaron, para dejar claro que tras la caída del dictador no volverían a sus casas.

En ese contexto, fue significativa la labor de recuperación de la memoria de sus luchas, como la del sufragio femenino en la década de los años 30 , encabezadas por el Movimiento Pro Emancipación de la Mujer Chilena (Memch), con quienes hilaron una continuidad histórica que devino en la fundación Memch '83. El Movimiento original había sido fundado el 11 de mayo de 1935, y en sus estatutos señalaba que era "... una organización femenina que persigue la emancipación integral y en especial la emancipación económica, jurídica, biológica y política de la mujer". ${ }^{3}$ Esto significaba que sus demandas eran diversas, y entre las más importantes destacamos su lucha por la obtención del voto femenino, obtenido en 1935 para elecciones municipales, y en 1949 para las presidenciales, y la legalización de aborto por razones de salud, económicas o sociales.

El Memch fue una organización plural desde el punto de vista político y de clase. Se congregaron mujeres militantes de partidos políiticos del centro y de la izquierda, así como mujeres independientes, activistas de la igualdad de género. Es importante destacar que su composición, desde el punto de vista políico, era similar al que tendría un año después el Frente Popular, coalición de radicales, socialistas y comunistas, de acuerdo a la políitica antifascista de la izquierda de la época en el mundo, y que en Chile llegó al poder en las elecciones de 1938, como antes lo había hecho en España y Francia. Cabe mencionar de manera especial entre sus fundadoras a Elena Caffarena y Olga Poblete. Caffarena fue, en 1926, una de las primeras mujeres que se tituló como abogada en Chile y en el desempeño de su oficio los derechos de las mujeres fueron su preocupación central. Poblete, eterna amiga y compañera de Elena, era profesora de historia de la Universidad de Chile, llegando a ser directora del Instituto Pedagógico por votación triestamental a principios de los años setenta. Ambas simpatizaban con el Partido Comunista. De hecho, una vez conseguido el derecho a voto, Elena Caffarena no pudo votar. La "Ley Permanente de Defensa de la Democracia" promulgada por Gabriel González Videla, radical que llegó al gobierno encabezando la coalición del Frente Popular en su tercer gobierno, puso fuera de la ley a comunistas. Ella, casada con un dirigente de dicho partido, fue borrada de los registros electorales.

Algunas autoras han señalado que el fin del Memch está relacionado con la obtención del voto por parte de las mujeres sufragistas, quienes, una vez lograda esa conquista, 
${ }^{4}$ Edda GAVIOLA et al., 2007, p.145. habrían "migrado" a los partidos políticos. No obstante, pensamos que muchas de ellas ya participaban de actividades militantes, y que la ley mencionada, conocida también como "ley maldita", erosionó la unidad del movimiento, así como la del mismo Frente Popular, que llegó a su fin con la ilegalización del Partido Comunista, hasta entonces parte de la coalición de gobierno. Las dirigentes del Memch siguieron trabajando en distintos frentes por los derechos de las mujeres y de todos los chilenos en general. El Movimiento había logrado el derecho a voto para las mujeres, que votaron por primera vez en una elección presidencial en 1952, pero también habían instalado en el debate público la necesidad de igualar condiciones laborales a hombres y mujeres, y legalizar el aborto, en algunas circunstancias, incluidas las razones socioeconómicas de la madre. De ahí la identificación transgeneracional, pues podía decirse que las mujeres chilenas de los años ochenta tenían menos derechos que a mediados de siglo, y la necesidad de recuperar una historia confiscada.

Una importante historiadora y activista de la época lo explicaba así, en 1986:

En las actuales circunstancias que vive el país, ha resurgido un movimient $o$ de mujeres que participa activa, creativa y valientemente en la lucha por la democracia. Junto con este movimiento comienza a despertar también, en los más variados círculos, una preocupación creciente por conocer, discutir y valorar la historia que nos legaron las mujeres que un día dijeron: "queremos votar en las próximas elecciones". ${ }^{4}$

Esta nueva generación de mujeres, que luchaba contra la dictadura y por sus demandas de género, se organizó también en otras instancias, y así fue como llegaron a la casa de Elena Caffarena, a principios de los años ochenta, a buscar su propia historia. Tanto ella como Olga Poblete habían estado trabajando incansablemente junto a las víctimas de la dictadura en la defensa de la vida y sus derechos, y es así como nace el Memch '83. En ese contexto, la producción teórica e historiográfica hecha por mujeres y para el movimiento de mujeres. Las mujeres feministas crearon Casa La Morada, en 1983, de donde salieron las más importantes reflexiones del feminismo chileno y sus más grandes pensadoras y activistas, como Julieta Kirkwood, socióloga, socialista y la más importante militante y teórica del feminismo chileno en la segunda mitad del siglo $X X$, quién tuvo una muerte temprana en 1985, a los 49 años. Una de sus obras más importantes y que aquí discutiremos fue Ser política en Chile, las feministas y los partidos, cuya primera edición data de 1982, y en el que emprende una 
${ }^{5}$ Elizabeth JELIN, 1998, p. 99.

${ }^{6}$ JELIN, 1998, p. 99. importante reflexión sobre la participación política de las mujeres del siglo XX en Chile.

\section{El dolor también es político}

Las feministas de los años ochenta compartieron la calle y las luchas de los movimientos de derechos humanos, sin embargo y visto desde hoy, obviaron el rol político que jugaban las mujeres organizadas en torno a la defensa de los derechos humanos y, muy particularmente, el de las integrantes de la Agrupación de Familiares Detenidos Desaparecidos, limitando su lucha al deber ser femenino y la extensión del rol materno que las llevaba a buscar a sus seres queridos movidas por los lazos afectivos que las vinculan con las víctimas. Para la mayoría de las autoras que se han referido al tema hasta hoy, este fenómeno se explica desde una perspectiva de género, que vincula a las mujeres a la familia y a los afectos, siendo su lucha en el espacio público nada más que una prolongación de un dolor privado.

Para Elizabeth Jelin:

Desde el principio hubo mujeres al frente del movimiento. El compromiso de la mayoría no provenía de convencimientos ideológicos democráticos, o de cálculos de estrategia política anti dictatorial. No era una lógica política, sino una lógica del afecto: fundamentalmente, mujeres directamente afectadas: madres, abuelas, familiares de víctimas, de desaparecidos o torturados, pidiendo y reclamando por sus hijos. La denominación de las organizaciones de mujeres alude a la primacía del vínculo familiar: Madres, abuelas, familiares, viudas, comadres. ${ }^{5}$

Culturalmente se ha designado a las mujeres el deber de cuidar a los ausentes y preservar su memoria. Desde el punto de vista de género, ese deber se vuelve a expresar en la búsqueda de los detenidos desaparecidos. Esto ha dado pie para que se afirme de manera reiterada en el cono sur que las mujeres familiares de detenidos desaparecidos se enfrentan por primera vez al espacio público.

De esta forma, explican, a mi juicio, el fenómeno, de la misma manera que lo harían los sectores más conservadores de la sociedad. Es decir, madres que salen a la calle a buscar a sus hijos, movidas por los afectos de la maternidad y las buenas emociones. Por otro lado, la represión sería exclusivamente masculina:

El contraste de género...es claro, y se repite permanentemente en una diversidad de contextos. Los símbolos del dolor y el sufrimiento personalizados tienden a corporizarse en mujeres, mientras que los mecanismos institucionales parecen 'pertenecer' a los hombres. ${ }^{6}$ 
En un sentido similar, Julieta Kirkwood señaló que este fenómeno responde a lo que denomina 'la política maternal', definida como una de las manifestaciones más sensibles de la simbólica mestiza de la mater en ciertas coyunturas de la vida nacional, en que las mujeres adquieren formas de protagonismo político. De esta manera, para la autora, las mujeres de la agrupación:

brotan como contestación a las maniobras del 'guerrero', que impuso el castigo para 'vencer' el 'caos', para legitimar su poder desde la violencia....Las mujeres así, ante el dolor y el quiebre de la continuidad vital, generaron una práctica social de protesta y reclamo, que emerge de su condición de sujeto procreador. ${ }^{7}$

Así, para las autoras mencionadas, lo que lleva a las mujeres a hacerse cargo de la tarea de encontrar a sus familiares está dada, principalmente, por su condición de procreadoras y por los lazos afectivos que las unen al ausente, y su lucha no es más que la prolongación de un dolor privado. Afirmaciones como estas han alimentado la premisa, no siempre real, de que las mujeres familiares de detenidos desaparecidos salían a la calle por primera vez, iniciándose en un camino absolutamente desconocido para ellas, y eso no siempre fue así, al menos en el caso de Chile. Desde una perspectiva histórica y de género podemos entender de manera más profunda sus luchas y motivaciones.

\section{Verdad y Justicia}

Los nombres de los detenidos desaparecidos son fundamentalmente masculinos. Setenta y dos casos del total corresponden a mujeres. Hay quienes han visto en estas cifras la explicación más evidente de la participación mayoritaria de mujeres en el movimiento de derechos humanos. Mujeres que buscan a sus parejas. Sin embargo, la tarea de encontrar a los desaparecidos y mantener viva su memoria fue asumida no solo por sus esposas, sino que también por sus madres, hermanas, e hijas. La Agrupación de Familiares de Detenidos Desaparecidos (AFDD) está constituida de manera mayoritaria, por mujeres con diversos vínculos familiares con las víctimas. Es decir, no es una organización de viudas. La mayoría de ellas se encontró inmediatamente después del golpe de Estado, buscando a sus familiares que habían sido detenidos, pero cuyo paradero era desconocido. Muchas de ellas se conocían de sus militancias políticas, otras se reconocieron a partir de ese momento, como parte de un colectivo. Se nombraron "mujeres democráticas". Algunas tuvieron suerte en su búsqueda, otras no. Estas últimas continuaron su tarea, hasta convertirse en la Agrupación de Familiares de Detenidos 
${ }^{8}$ Agrupación de Familiares de Detenidos Desaparecidos, material de difusión. Santiago. Pág. 3. Apud Carla Peñaloza PALMA. Rebeldes $y$ Santas. Un análisis del rol político de las mujeres de la AFDD de Chile. 17 sept, 2013. Disponible en: http:/ /www.alsurdetodo.com/?p=217. Acceso en: sin fecha.

${ }^{9}$ Diario La segunda, Santiago, 25 de julio de 1975.
Desaparecidos, en la medida que el gobierno no reconocía la detención de sus seres queridos.

Nacimos dicen en su declaración de principios como organización para defender la vida. La denuncia fue nuestra primera acción para rescatar con vida a nuestros seres queridos secuestrados y mantenidos en recintos secretos de tortura. En la Agrupación de Familiares de Detenidos Desaparecidos nos fortalecimos día a día y adquirimos la fuerza necesaria para enfrentar la brutal represión de la dictadura militar. Hoy seguimos luchando para mantener viva la memoria de los nuestros, exigiendo Verdad y Justicia. En este devenir, a pesar del tiempo, nos hemos ido transformando en protagonistas de una historia que ninguno de nosotros hubiese querido vivir. ${ }^{8}$

Así, al alero de las iglesias, que pocos días después del golpe militar se constituyeron en el Comité Pro-paz, la AFDD da sus primeros pasos. Luego en la Vicaría de la Solidaridad (1976), dependiente de la Iglesia Católica y creada una vez que Pinochet ordenó cerrar el Comité, encontrarán refugio a su dolor y se potenciarán como colectivo. Para ellas, la fecha oficial de fundación es julio de 1975, año en que se monta la 'operación colombo' como parte del plan cóndor, en la que se atribuye la identidad de 119 chilenos detenidos y desaparecidos, y de cadáveres de víctimas argentinas. La información fue difundida por la Revista Lea, de Argentina y O'dia de Curitiba, Brasil, y atribuían las muertes a enfrentamientos entre compañeros del mismo movimiento. En Chile, el diario La Segunda hace eco de la noticia como parte de una acción planificada, y titula su portada: "exterminan como ratas a miristas", 9 aludiendo a la militancia de la mayoría de los 119. A partir de su temprana organización, podemos observar el esfuerzo por saber la verdad sobre el paradero de sus familiares, exigir justicia y castigo a los culpables, pero también en una dimensión más universal, que hechos como estos no vuelvan a ocurrir en ningún otro tiempo ni lugar.

No podemos entender su lucha sino entendemos previamente que se enfrentaron a una forma de represión brutal e insospechada que hubo que inventar un término para referirse a sus víctimas: Detenidos Desaparecidos. A partir de sus testimonios hemos podido analizar el duelo privado, que asume particulares características por tratarse de una experiencia límite y desconocida hasta entonces, y por otra parte su lucha en el espacio público por la verdad y la justicia. El duelo privado se convierte en un asunto de carácter público. Los familiares, junto con el dolor, deben asumir la tarea de exigir a las instituciones una respuesta a la situación de sus familiares: ¿dónde están? Se inicia así un proceso por develar 
los secretos de un Estado que no protege, sino que agrede a sus ciudadanos. Bajo esa irracionalidad de buscar respuestas entre los que ocultan sus crímenes, será necesario crear solidaridades más allá del ámbito familiar. La sociedad chilena debe saber lo que está ocurriendo con muchos de sus compatriotas. Mi hipótesis es que la organización de las mujeres en torno a la AFDD fue posible por las particularidades del siglo XX "de las mujeres" de Chile. Las mujeres habían experimentado un paulatino proceso de incorporación al espacio público y en ese contexto, y sobre todo en momentos de crisis social, habían participado de las luchas políticas del movimiento popular. Comenzaron a organizarse a fines del siglo XIX, en clubes y mutuales, donde muchas aprendieron a leer y organizarse, habían estado presentes en las primeras huelgas del siglo XX, también en las marchas del hambre de 1918 que reclamaba por el alza de precios de los alimentos y exigía cambios sociales y políticos profundos para el país, en la Asamblea Constituyente de 1925, y en las luchas por el sufragio y la ciudadanía plena de las mujeres, conquistados en 1949

Las mujeres chilenas del siglo XX se habían incorporado masivamente a los partidos políticos y organizaciones sociales de la época. Además, pertenecían a una generación de chilenos que habían visto en el espacio público el lugar privilegiado para resolver sus conflictos, manifestar adhesiones o disensos. Era el lugar de logro de las principales conquistas del movimiento popular y los más importantes avances democráticos, cuyo momento cúlmine fue el triunfo de Salvador Allende y la Unidad Popular. Tras el golpe militar y la confiscación de todos los derechos ciudadanos, se convertía en un espacio necesario de recuperar. Para la mayoría de las mujeres la desaparición significó involucrarse de lleno en las actividades de los organismos de derechos humanos. En muchos casos esta situación también vino acompañada de otros quiebres como despidos del trabajo, pérdida de amistades que por miedo o incredulidad se alejaban (en algunos casos esto se extiende al propio ámbito familiar), cambios constantes de domicilio o lisa y llanamente el camino del exilio, y en general una situación de inestabilidad derivada de su relación familiar con el desaparecido, su vinculación a las organizaciones de familiares o a sus propias militancias políticas. La tradición partidaria de la izquierda había ido formando una cultura políica, que no sólo abarcaba a sus militantes. En ese proceso de socialización se formaron políticamente muchas generaciones, antes del golpe militar. Este era un espacio donde la familia y los amigos formaban parte de la red partidaria y en ese contexto, por ejemplo, la militancia de familias completas no era un fenómeno aislado y la vida privada y la pública tenía un límite impreciso. Parejas 
e hijos se formaron en este mundo colectivo. Esta formación política previa, entendida como el derecho a la participación ciudadana y sobre todo colectiva, en su más amplio sentido, se expresó de la manera más dramática a partir del golpe de Estado. Este contexto las pondrá a prueba y actuaran en consecuencia con su propia historia. Las mujeres familiares de las víctimas de la represión, con una conciencia y experticia previa en ámbitos de participación, las define como actores sociales de primera línea en una situación vital límite como es la represión estatal, y las lleva a tomar decisiones de connotación política. En ese sentido, el nudo central de la acción de las mujeres de la AFDD estará dado por el gran paso que dan desde el duelo doméstico (que no dejan de lado) hacia el espacio público. Superan el ámbito privado y del mero recuerdo, para transformarse en portadoras de la memoria colectiva de la nación herida, y ese será su gran mérito.

En el camino elegido por las mujeres chilenas comienzan a organizarse en torno a la Agrupación de Familiares de Detenidos Desaparecidos, enfrentando a la dictadura para saber el paradero de sus seres queridos. Se habían conocido o muchas veces reencontrado a la salida de los centros de detención, inquiriendo información sobre sus familiares. Muchas se conocían de sus militancias políticas previas, lo que favoreció de manera considerable las posibilidades de organizarse y actuar colectivamente, así como el surgimiento de liderazgos al interior de la organización. Para ello, lo importante era actuar de manera colectiva, reivindicando el proyecto político abortado por la fuerza y quienes habían encarnado ese proyecto. Posteriormente, frente a la negación de las autoridades de revelar el paradero de los presos, se agregó la necesidad de denunciar lo que parecía ser una voluntad ex profesa de ocultación y de denegación de los hechos. Se trataba entonces de denunciar lo que era un efecto - los cuerpos ocultados y por lo tanto invisibles - y a su vez una decisión: hacer desparecer, mentir abiertamente cuando se declaraba no saber dónde estaban los cuerpos e incluso negar la existencia legal de los individuos reclamados por sus familiares.

Un hito importante dentro de la naciente Agrupación lo constituyó la desaparición de la casi totalidad del Comité Central del Partido Comunista, y la incorporación de sus familiares a la organización, a fines de 1976. La gran mayoría era militante del mismo partido, y ocuparon la dirigencia de la Agrupación de Familiares de Detenidos Desaparecidos, con Sola Sierra, militante comunista desde su adolescencia, tras la desaparición de su esposo Waldo Pizarro, quién será presidenta de la AFDD por seis periodos consecutivos, hasta el día de su muerte. En junio de 1977 la AFDD realiza su primera manifestación pública. Veintiséis familiares iniciaron 
${ }^{10}$ Sola SIERRA, 1997, p. $23-25$

11 SIERRA, 1997, p.121.

${ }^{12}$ Sola Sierra, Presidenta de la AFDD hasta la fecha de su muerte en 1999.

${ }^{13}$ Iván LJUBETIC, 2000, p.134. una huelga de hambre que duró diez días. La acción llegó a término con el compromiso de la Junta Militar ante el Secretario General de Naciones Unidas de investigar las denuncias de desaparición forzada de personas. ${ }^{10}$

Comenzaba la etapa más pública de la AFDD y la disminución ostensible de la desaparición forzada como mecanismo de represión. Poco a poco, fueron crecientes las movilizaciones de denuncia y en ese contexto la red de solidaridades creadas por la AFDD con otras organizaciones, con los partidos políticos, y en definitiva con todos aquellos chilenos que lucharon en los años ochenta por el retorno a la democracia. El respeto a los derechos humanos y la memoria de las víctimas se convirtieron en un pilar fundamental de resistencia contra la dictadura. De hecho, la movilización de esos años se tradujo en que el programa de gobierno de la Concertación de Partidos por la Democracia, para las primeras elecciones democráticas, señalara entre sus tareas la derogación de la Ley de Amnistía. Por otra parte, en 1992 la AFDD, junto con otras organizaciones de familiares de detenidos desaparecidos de todo el continente, lograron que la Asamblea General de Naciones Unidas aprobara la Declaración sobre la Protección de Todas las Personas contra las Desapariciones Forzadas. ${ }^{11}$

Sin duda que la detención de Pinochet en Londres marcó un cambio de escenario. Constituyó un avance significativo, en tanto abrió el debate a nivel nacional e internacional, y ya nadie pudo desconocer las dimensiones de las violaciones a los derechos humanos ocurridas en nuestro país, así como quiénes son sus responsables. Como lo planteara Sola Sierra ${ }^{12}$ en su día:

El arresto de Pinochet en Londres es nuestro logro y el de todos aquellos que -en cualquier parte del mundohan contribuido a esta gesta de impedir la impunidad y abrir los caminos de la justicia. Pero hoy el peligro más grave lo representan quienes intentan -en medio del secreto y el silencio- imponer pactos espurios que sellen la impunidad...Queremos decirlo con claridad una vez más, en Chile solo habrá verdadera democracia cuando haya verdad y justicia. ${ }^{13}$

En definitiva una tarea que no acaba y que se enfrenta a grandes desafíos, una historia con un dramático comienzo y que nadie hubiese querido vivir. De esta manera, se han ido tejiendo solidaridades y luchas. Traspasando las barreras que imponen la violencia, el silencio y el miedo, las mujeres chilenas iniciaron hace ya casi treinta años la difícil tarea de reconstruir el tejido político, al mismo tiempo que defienden la memoria de sus seres queridos, en un complejo entramado que vincula lo privado con lo universal. Sabiendo que su tragedia personal es al mismo tiempo la trasgresión violenta 
de los derechos fundamentales de la sociedad occidental, su lucha ha sido personal y política, pero, sobre todo, ética. En definitiva y desde una perspectiva de género estamos en presencia de un quiebre significativo ante los supuestos modos de ser y de actuar de las mujeres. En su calidad de familiares de víctimas de la represión, cumplieron con sus deberes privados en torno al resguardo de los ritos de la muerte, normados culturalmente a través de los siglos, al mismo tiempo que desde un trabajo político, en su calidad de militantes y ciudadanas portadoras de la memoria colectiva de la nación que emplazaban a los temibles y supuestamente invencibles poderes del Estado.

La dictadura se enfrentó a algo inédito e inesperado y que no podían controlar. Había algo diferente en la tarea de estas mujeres. En ninguna de las grandes catástrofes del siglo XX es posible observarlas cumpliendo ese rol. Ni en la guerra civil española, ni en torno al holocausto, y quién sabe si con su presencia, la historia pudo haber sido otra. Desde el punto de vista de género, el duelo y la memoria de los suyos son deberes asignados históricamente a las mujeres, rol cumplido a cabalidad por la AFDD. Sin embargo, estas mujeres ocuparon la plaza pública, colectivizando la memoria, para exigir Verdad y Justicia. La irrupción en el espacio público y la elaboración de un discurso que nace del duelo, pero se proyecta hacia la defensa de los postulados de la modernidad, es lo que marca un quiebre en relación a las experiencias conocidas hasta ese momento, y que en Chile será un sello distintivo. El largo camino recorrido por las mujeres de la AFDD da cuenta de una lucha colectiva, trascendiendo la lógica de lo individual, para instalarse en el espacio público como una movilización política contra la dictadura. El rol de las mujeres no se limitó a la búsqueda de sus seres queridos. Ellas se organizaron, actuaron y en definitiva reivindicaron una voluntad política:

...porque además de unirnos lazos de sangre a nuestros familiares, también entendemos que encontrar a los detenidos desaparecidos, establecer la verdad y hacer justicia es una obligación para las posibilidades futuras de la paz y la única certeza que estos actos inhumanos no volverán a repetirse. ${ }^{14}$

Son a su vez portadoras de la memoria de un proyecto político abortado (la Unidad Popular), en tanto son parte de quienes lo encarnaron "mujeres, hombres, jóvenes e incluso niños, gente sencilla de nuestro pueblo que luchó decididamente para construir un país más justo y más humano", ${ }^{15}$ encabezado por la figura de Salvador Allende, reivindicado por la AFDD como la primera víctima del terrorismo de Estado. Van a denunciar la ruptura del sistema democrático como la 
${ }^{16}$ No hicimos referencia en este trabajo al caso Argentino, por no conocerlo tan a fondo, y sobre todo porque asumimos que en ambos casos hay mucho de similitudes pero tal vez mucho más de diferencias. Por ejemplo, es posible señalar que algunos grupos de madres han levantado discursos desde lo afectivo revindicando que su lucha es por sus hijos, quienes las hicieron salir por primera vez a la calle, más que un lucha política. Entendemos que hay trabajos en curso que también cuestionan estos supuestos, pero la bibliografía existente hasta ahora no da cuenta de ello. causa de los atropellos a los derechos fundamentales de las personas, y van a recuperar los espacios de participación, confiscados a partir del golpe militar. Van a interpelar al Estado, a través de sus instituciones, para exigir respuesta y denunciarlo como responsable de la suerte de sus familiares y de todas las víctimas de la represión, en la clara convicción de que lo eran por razones políticas.

Todo lo anterior da cuenta de una estrategia que no sólo se basa en los comportamientos tradicionalmente aceptados en torno al deber ser femenino, utilizado, sin duda, para esquivar la represión. Es una estrategia que se entiende de mejor manera si consideramos los cambios de los roles de género, a través de un siglo de participación pública de las mujeres. A partir de la desaparición de sus familiares, se comprometieron en una batalla por la verdad y la justicia, que es en definitiva la exigencia del respeto pleno de los derechos humanos de todos los hombres y mujeres. Es una batalla por la memoria individual y colectiva: la memoria de los ausentes y la de una sociedad enfrentada al horror, que debe decir: Nunca Más.

\section{Consideraciones finales}

Sin duda que tras esta reflexión surge la pregunta por las lecturas sobre la organización y lucha de las familiares y detenidos desparecidos, hechas por diversos sectores y, en este caso, el feminismo. En primer lugar, habría que señalar que para todos los chilenos la desaparición forzada de personas fue un hecho inédito y tremendamente violento, como para poder tener las herramientas que permitieran explicarlo en su momento. No era fácil, ni emocional, ni racionalmente, dar contexto y contenido a una forma tan perversa de represión. En segundo lugar, las mujeres feministas no vieron, porque en efecto no había, demandas propias de género en la lucha de las mujeres de la Agrupación, y eso las llevó a pensar que ni siquiera había acción política por lo que no podían compararse sus luchas. Considerando los lazos afectivos que unían a las mujeres con las víctimas, no era impensable que se tratara de una lucha privada, circunscrita al ámbito familiar. Discursos de realidades similares, como es el caso de Argentina, era posible pensar que se trataba de un mismo fenómeno. ${ }^{16}$ Sin embargo no cabe pensar que sus manifestaciones públicas no tuvieran carácter político. Pienso que son razones precisamente políticas, las que llevaron a obviar ese aspecto para reafirmar la dicotomía públicoprivado. Las Mujeres feministas se sintieron más identificadas con las mujeres de la década del 30 , sin advertir que se trataba de las mismas mujeres que luego se convertirían en activistas de la defensa de los derechos humanos. 
${ }^{17}$ GAVIOLA et alt., 2007, p. 148.
Para muchos investigadores sociales en Chile, hay una disociación entre el movimiento social y los partidos políiticos. Sin embargo, la izquierda organizada en partidos políticos siempre ha estado presente en el movimiento social más importante del siglo. El Memch como movimiento desapareció tras lograr el derecho a voto. Para Gaviola, ${ }^{17}$ una de las causas fue que las mujeres habían migrado a los partidos políticos:

Este proceso se debió a la imposibilidad de conseguir una unidad perdurable entre mujeres de diversas clases sociales, con distintas necesidades y aspiraciones; y a la plena vigencia de una ideología sexista.

Pero lo cierto es que fueron las mujeres militantes de partidos políiticos las que habían formado el Memch, y conflictos internos graves entre estos determinaron, a mi juicio, el fin de esta alianza (la ruptura del frente popular por causa de la ilegalización del partido comunista, por parte del gobierno radical, del cual formaban parte. Todo esto en el contexto de la Guerra Fría). Estas mismas mujeres militantes aparecerán luego para buscar a sus familiares, y serán parte de la lucha en contra de la dictadura desde un comienzo, y también en los revueltos años ochenta, junto a las feministas, a los estudiantes, los trabajadores, y al pueblo de Chile en general, y luchando contra la impunidad hasta el día de hoy.

\section{Referencias}

GAVIOLA, Edda et alt. Queremos votar en las próximas elecciones. Historia del movimiento sufragista chileno, 19131952. (2a. Ed). Santiago, Chile: LOM Ediciones, 2007.

HUNNEUS, Carlos. El régimen de Pinochet. Santiago, Chile: Editorial Sudamericana, 2000.

JELIN, Elizabeth. Los trabajos de la Memoria. Buenos Aires, Argentina: Editorial Siglo XXI 1998, pág. 99.

KIRKWOOD, Julieta. Ser política en Chile. (2a.ed.) Santiago, Chile: Editorial Cuarto Propio, 1990.

LJUBETIC, Iván. Sola Sierra, una imprescindible. Santiago, Chile: Editorial El Pan Nuestro, 2000.

POBLETE, Olga. Una mujer: Elene Caffarena. Santiago, Chile: Editorial Cuarto Propio, 1993.

SIERRA, Sola; BECERRA, Gustavo; DÍAZ, Viviana. 20 años de historia de la Agrupación de Familiares de Detenidos Desaparecidos de Chile, Santiago, 1997.

[Recebido em 9 de fevereiro de 2015 e aceito para publicação em 15 de março de 2015] 
Mourning on the Streets: Women, Politics and Human Rights Under the Chilean Dictatorship (1973-1989)

Abstract: The women of the families of the Chilean dictatorship's victims gathered together very early to find their loved ones and demand truth and justice. However, feminist studies have relegated them to the role of women-mothers who go out of their homes for the first time to fulfill a traditional role, such as caring for their families, without attributing a political character to their demonstrations. In this paper, we propose to call into question this analysis, suggesting that those women played an important role in the defense of human rights, as well as in the re-articulation of the social fabric destroyed after the coup. They became political frontline actors in the public space, to demand the truth about the fate of their loved ones, challenging the regime and its legitimacy, defending, in that way, the human rights that had been confiscated from all Chileans. Keys words: Women; dictatorship; human rights; feminism. 